\title{
Kemampuan Berbicara Anak Di Tk Pertiwi Desa Rajabasa Lama Kecamataan Labuhan Ratu Kabupaten Lampung Timur
}

\author{
Mega Mulyani' ${ }^{1}$, Ulwan Syafrudin ${ }^{1}$, Rizky Drupadi ${ }^{1}$ \\ ${ }^{1}$ FKIP, Universitas Lampung, Jl. Prof. Dr. Sumantri Brojonegoro No. 1 \\ E-mail: megamulyani074@gmail.com
}

Received: 15 Oktober 2020

Accepted: 1 November 2020

Published: 5 November 2020

Abstract. Children's Speaking Ability at Kindergarten Pertiwi, Rajabasa Lama Village, Labuhan Ratu District, East Lampung Regency. This research is motivated by the lack of children's speaking ability in answering questions given by the teacher and the inability of the child to simply retell the contents of the stories they have heard. The purpose of this study was to improve speaking skills of group A children in TK Pertiwi Desa Rajabasa Lama. The subjects of this study were 15 children. The data collection techniques used were observation (observation sheets), interviews (interview grids for teachers), and documentation (notes during the activity, pictures or photos, and RKH). The data analysis technique was done using quantitative descriptive. The children's speaking ability reached $48.14 \%$ and a decrease in the score obtained reached $6.67 \%$. The teacher provides motivation and rewards in the form of "Bintangs" to children who have an increase in learning.

Keywords: speaking ability, early childhood

\begin{abstract}
Abstrak. Kemampuan Berbicara Anak Di Tk Pertiwi Desa Rajabasa Lama Kecamataan Labuhan Ratu Kabupaten Lampung Timur. Penelitian ini dilatarbelakangi oleh kurangnya kemampuan berbicara anak dalam menjawab pertanyaan yang diberikan oleh guru serta ketidakmampuan anak dalam menceritakan kembali isi cerita yang telah didengarnya secara sederhana. Tujuan Penelitian ini adalah untuk meningkatkan keterampilan berbicara pada anak kelompok A di TK Pertiwi Desa Rajabasa Lama. Subjek penelitian ini sebanyak 15 anak. Teknik pengumpulan data yang digunakan adalah observasi (lembar observasi), wawancara (kisi-kisi wawancara untuk guru), dan dokumentasi (catatan catatan selama proses kegiatan berlangsung, gambar atau foto, dan RKH). Teknik analisis data dilakukan secara deskriptif kuantitatif. Kemampuan berbicara anak mencapai $48,14 \%$ dan terjadi penurunan skor yang didapat mencapai 6,67\%. Guru memberikan motivasi dan reward berupa "Tanda Bintang" kepada anak yang memiliki peningkatan dalam belajar.
\end{abstract}

Kata kunci: kemampuan berbicara, anak usia dini, 


\section{PENDAHULUAN}

Peran orang tua sangat penting dalam mendidik anak, karena pada saat awal pendidikan seorang anak terdapat dari lingkungan keluarga terutama orang tua. Anak usia prasekolah merupakan anak yang memiliki usia sekitar 3-6 tahun, pada usia tersebut orang tua dapat menitipkan anak-anaknya ke sebuah lembaga sekolah yang dapat membantu dan mendidik anaknya sesuai dengan pertumbuhan dan perkembangannya. Salah satunya di TK (Taman Kanakkanak), pembelajaran di TK lebih dikenal dengan bermain sambil belajar. Taman Kanak-kanak ini bertujuan untuk memberikan kesiapan bagi anak untuk kejenjang sekolah dasar dan menjadikan anak cerdas dalam beremosi maupun berkarakter yang baik. Salah satu aspek perkembangan yang sangat penting bagi anak yaitu bahasa. Melalui bahasa anak dapat menyampaikan keinginan, pikiran, harapan, maupun permintaan serta dapat bergaul dengan sesama di lingkungan anak. Ketika anak dapat mempelajari bahasa maka anak dapat memiliki keterampilan bahasa yang baik, sehingga dalam hal ini anak mudah berkomunikasi dengan lingkunganya. Terdapat beberapa aspek Pendidikan Anak Usia Dini yaitu nilai agama dan moral, kognitif, fisik motorik, bahasa, sosial emosional dan seni.

Perkembangan yang menjadi fokus dalam karya ilmiah ini adalah aspek perkembangan bahasa tentang kemampuan berbicara anak. Menurut Elizabeth B. Hurlock dalam bukunya Perkembangan Anak, mengungkapkan bahwa bicara adalah alat komunikasi untuk saling menukarkan pikiran dan perasaan anak. Sedangkan menurut Tarigan berbicara merupakan suatu alat untuk mengkomunikasikan gagasangagasan yang sudah disusun dan dikembangkan sesuai dengan kebutuhan sang pendengar dan penyimak. Proses perkembangan dan pendidikan anakanak, biasanya lebih belajar dari mencontoh atau meniru orang dewasa. Orang dewasa merupakan hal yang dapat dicontoh bagi anak-anak. Sehingga yang dilakukan oleh anak dapat juga dapat pengaruh dari orang disekelilingnya. Kurangnya kemampuan berbicara anak terlihat dari kemampuan anak yang sulit berkomunikasi dengan bahasa lisan, sulit mengemukakan pendapat dengan sederhana dengan orang lain maupun dengan dirinya sendiri, sulit untuk menceritakan pengamalannya sendiri dengan sederhana, dan kemampuan kosakata anak pun masih terbatas (Dhieni, et.al, 2005).

Pada masa ini, anak-anak mengalami masa peka atau masa sensitif dalam menerima berbagai upaya pengembangan seluruh potensi yang dimilikinya. Masa ini merupakan masa terjadinya pematangan fungsi-fungsi fisik dan psikis yang siap merespon rangsangan yang diberikan oleh lingkungan. Sejauh ini, Perkembangan bahasa anak usia dini memang masih jauh dari sempurna. Sehingga, seorang pendidik memiliki peranan penting dalam proses pembelajaran anak usia dini agar dapat mengembangkan bahasa anak dengan baik. Pendidik perlu mengetahui pengembangan bahasa anak dan strategi pembelajaran yang dapat mengembangkan kemampuan bahasa anak (Suhartono, 2005).

Berdasarkan permasalahan tersebut, keterampilan berbicara anak pada kelompok A di TK Pertiwi masih belum optimal. Belum optimalnya keterampilan berbicara anak dikarenakan masih sedikitnya memberikan kesempatan untuk anak mengungkapkan (ide, pikiran, gagasan dan perasaan) 
melalui komunikasi lisan, metode pembelajaran masih kurang bervariasi sehingga anak cepat merasa jenuh atau bosan mengikuti pembelajaran. Guru sangat berperan dalam proses pembelajatan untuk meningkatkan kemampuan berbicara anak.

\section{METODE}

Penelitian ini merupakan penelitian deskrpsi kuantitatif. Teknik pengumpulan data dalam penelitian ini yaitu teknik observasi, wawancara dan dokumentasi. Teknik observasi digunakan apabila penelitian berkenaan dengan perilaku manusia, proses kerja, gejala-gejala alam, dan responden tidak terlalu besar. Pengamatan dengan pengamatan terhadap kegiatan yang sedang berlangsung serta dikaitkan dengan menggunakan pedoman observasi dalam bentuk skala yang dibuat dalam panduan instrumen penelitian yang telah teruji validitas dan rehabilitasnya (Sugiyono, 2010).

Skala pengukuran yang digunakan pada penelitian ini yaitu menggunakan skala likert dimana jawaban setiap item instrumen memiliki gradasi dari sangat positif sampai sangat negatif. Instrumen penelitian dibuat ceklist.

Penelitian ini dilaksanakan pada bulan November-Januari 2021 di TK Pertiwi Desa Rajabasa Lama Kecamatan Labuhan Ratu Kabupaten Lampung Timur. Obyek penelitian sebanyak 15 orang anak. Fokus penelitian adalah kemampuan berbicara pada anak kelompok A TK Pertiwi Desa Rajabasa Lama Kecamatan Labuhan Ratu Lampung Timur.

Analisis data yang dipergunakan dalam penelitian ini yaitu Analisis Statistik Diskriptif dan Analisis Diskriptif Kuantitatif. Analisis Statistik Diskriptif merupakan suatu cara pengolahan data yang dilakukan dengan jalan menerapkan teknik dan rumusrumus statistik deskriptif seperti distribusi frekuensi, grafik, angka ratarata (Mean), median (Me), modus (Mo) untuk menggambarkan keadaan suatu objek tertentu sehingga diperoleh kesimpulan umum. Sedangkan metode analisis deskriptif kuantitatif adalah suatu cara pengolahan data yang dengan jalan menyusun secara sistematis dalam bentuk angka-angka dan atau presentase keadaan suatu obyek yang diteliti sehingga diperoleh kesimpulan umum (Agung, 2010).

\section{HASIL DAN PEMBAHASAN}

Berdasarkan hasil analisis diketahui bahwa dari 15 orang responden yang diteliti terdapat presentase kemampuan berbicara diamati dari saat tanya jawab atau saat guru menerangkan didalam kelas hanya ada 3 orang aktif saja dalam tanya jawab dan berani berkomentar dengan lebih dari satu kalimat saat diterangkan oleh guru. Data kelas anak dalam kemampuan berbicara secara rinci dapat dilihat pada tabel 1 .

Tabel 1. Kemampuan berbicara anak

\begin{tabular}{|c|c|c|c|c|c|c|c|c|c|c|c|c|}
\hline \multirow[t]{2}{*}{$\begin{array}{l}\text { No } \\
\text { res }\end{array}$} & \multicolumn{3}{|c|}{$\begin{array}{l}\text { Melafalkan } \\
\text { bunyi }\end{array}$} & \multicolumn{4}{|c|}{ Kosa kata } & \multicolumn{4}{|c|}{$\begin{array}{c}\text { Menyusun } \\
\text { kalimat }\end{array}$} & \multirow[t]{2}{*}{$\begin{array}{l}\text { Sk } \\
\text { or }\end{array}$} \\
\hline & 1 & 2 & 34 & 1 & 2 & 3 & 4 & 1 & 2 & 3 & 4 & \\
\hline A & & V & & & V & & & V & & & & 1 \\
\hline B & & & V & & V & & & & V & & & 3 \\
\hline $\mathrm{C}$ & & V & & V & & & & & & V & & 5 \\
\hline D & & & V & & & V & & & & & V & 8 \\
\hline E & & V & & V & & & & & V & & & 3 \\
\hline $\mathrm{F}$ & & & V & & & V & & & & V & & 6 \\
\hline G & & V & & & V & & & V & & & & 2 \\
\hline $\mathrm{H}$ & & & V & & & V & & & & V & & 6 \\
\hline I & V & & & V & & & & V & & & & 0 \\
\hline $\mathrm{J}$ & & V & & & V & & & & V & & & 4 \\
\hline $\mathrm{K}$ & & & V & & & V & & & & V & & 5 \\
\hline $\mathrm{L}$ & & V & & V & & & & V & & & & 1 \\
\hline M & & V & & & V & & & & V & & & 2 \\
\hline $\mathrm{N}$ & & & V & & & V & & & & & V & 6 \\
\hline $\mathrm{O}$ & & V & & & V & & & & V & & & 0 \\
\hline & & & & & mlah & & & & & & & 52 \\
\hline & & & & senta & & & & & & & 8,14 & \\
\hline
\end{tabular}

Keterangan : 
$\mathrm{BB}=$ Belum berkembang, $\mathrm{MB}=$ Mulai berkembang, $\mathrm{BSB}=$ Berkembang sangat baik, $\mathrm{BSH}=$ Berkembang sesuai harapan.

Skor 0-3 = Kurang Baik, Skor 4-6 = Baik, Skor 79 =Sangat Baik

Berdasarkan tabel diatas maka dilihat bahwa kemampuan berbicara anak masih rendah atau tidak baik. Hal ini dilihat dari hasil kemampuan berbicara anak secara keseluruhan hanya $48,14 \%$ dari yang diinginkan. Hal ini menandakan bahwa perlu adanya perbaikan terhadap kemapuan berbicara anak, dibantu oleh guru yang dapat mendorong kemauan anak untuk terus belajar.

Hasil analisis berdasarkan pendidikan terakhir diketahui bahwa terdapat tiga kategori skor dengan jumlah presentase terbesar yakni skor 0-3 sebanyak 8 orang $(53,3 \%)$. Sebaran lainnya yaitu skor 4-6 sebanyak 6 orang (40\%), skor 7-9 didapatkan anak sejumlah 1 orang $(6,67 \%)$. Secara rinci dapat dilihat pada tabel 2 .

Tabel 2. Skor kemampuan berbicara anak

\begin{tabular}{|l|c|c|c|c|c|c|}
\hline \multirow{2}{*}{$\begin{array}{l}\text { Observasi } \\
\text { /Skor }\end{array}$} & \multicolumn{2}{|c|}{$\begin{array}{c}0-3= \\
\text { Kurang Baik }\end{array}$} & \multicolumn{2}{c|}{$4-6=$ Baik } & \multicolumn{2}{|c|}{$\begin{array}{c}7-9=\text { Sangat } \\
\text { Baik }\end{array}$} \\
\cline { 2 - 7 } & $\begin{array}{c}\text { Jlh } \\
\text { Anak }\end{array}$ & $\%$ & $\begin{array}{c}\text { Jlh } \\
\text { Anak }\end{array}$ & $\%$ & $\begin{array}{c}\text { Jlh } \\
\text { Anak }\end{array}$ & $\%$ \\
\hline $\begin{array}{l}\text { Kemampuan } \\
\text { berbicara }\end{array}$ & 8 & $\begin{array}{c}53,3 \\
\%\end{array}$ & 6 & $40 \%$ & 1 & $6,67 \%$ \\
\hline
\end{tabular}

Reliabilitas adalah suatu instrument cukup dapat dipercaya untuk digunakan sebagai alat pengumpul data karena instrument tersebut sudah baik. Reliabel artinya dapat dipercaya jadi dapat diandalkan (Arikunto, 2010).

Adapun hasil uji reliabilitas instrumen penelitian dengan menggunakan teknik Reliability analysis sebagai berikut:

Tabel 3. Hasil Uji Reliabilitas Instrumen Keterampilan Berbicara Reliability Statistics

\begin{tabular}{|c|c|}
\hline $\begin{array}{c}\text { Cronbach's } \\
\text { Alpha }\end{array}$ & N of Items \\
\hline 0,76 & 12 \\
\hline
\end{tabular}

Pada uji reliabilitas dikatakan tinggi apabila menghasilkan >0,6, sedangkan $r_{a c}$ yang dihasilkan adalah 0,76. Sehingga dapat dikatakan instrumen tersebut reliabilitasnya dapat dikatakan tinggi.

Perbandingan grafik setiap skor kemampuan berbicara dari jumlah anak 8 yang bernilai kurang baik, 6 orang yang bernilai baik, dan satu orang bernilai sangat baik. Grafik tentang peningkatan skor kemampuan berbicara dapat dilihat pada grafik 1 .

Grafik 1. Skor peningkatan kemampuan berbicara anak.

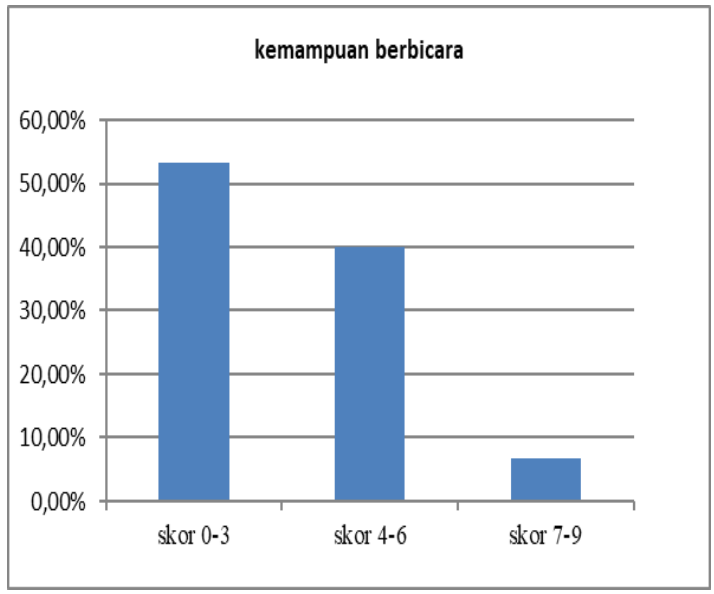

\section{PEMBAHASAN}

Berdasarkan hasil observasi yang telah dilakukan dapat diketahui bahwa anak kelompok A belum dapat berbicara dengan baik mencakup melafalkan bunyi, kosa kata dan menyusun kalimat. Dalam penelitian ini anak diharapkan mampu aktif dan mengalami peningkatan meski ada anak yang belum mengalami peningkatan yang sesuai dengan yang diharapkan namun dengan lamanya waktu anak tersebut akan meningkat sesuai yang diinginkan. Setiap anak memang memiliki karakteristik yang berbeda dan juga perkembangan dalam berbicara juga dipengaruhi oleh beberapa 
hal tidak hanya di sekolah namun juga di lingkungannya seperti pendapat dari Hurlock (1999) terdapat beberapa faktor yang dapat mempengaruhi tingkat perkembangan bahasa anak yaitu mengemukakan kondisi yang dapat menimbulkan perbedaan dalam bahasa yaitu kesehatan, kecerdasan, keadaan sosial ekonomi, jenis kelamin, keinginan berkomunikasi, dorongan, ukuran keluarga, urutan kelahiran, metode pelatihan anak, kelahiran kembar, hubungan dengan teman sebaya. Pada kutipan tersebut, sesuai dengan penelitian ini bahwa ada beberapa anak yang memang kurang mampu berbicara dipengaruhi oleh keadaan sosial ekonomi yang berbeda anak yang cenderung aktif dan cerdas dalam mengungkapkan ide gagasannya juga dipengaruhi oleh kondisi ekonomi keluarganya.

Terdapat beberapa masalah yang membuat peningkatan kemampuan berbicara anak kurang maksimal, seperti anak yang cenderung diam masih duduk dibelakang, belum berani bertanya, belum bisa menjawab pertanyaan, sehinga masih belum sesuai indikator. Dari data beberapa faktor yang skor yang dihasilkan terjadi penurunan jumlah anak sebesar $6,67 \%$ pada jumlah skor tertinggi sekitar 7-9, hal ini karena banyaknya anak yang masih senang duduk di belakang dan hanya diam saja saat ditanya dan masih ada banyak anak yang memiliki skor rendah, hal lain diduga karena keadaan orang tua dan ekonomi dalam keluarga anak tersebut sehinga masih perlu diberikan bimbingan khusus dan motivasi dari guru.

\section{SIMPULAN}

Berdasarkan hasil 15 anak pada penelitian ini, diperoleh kesimpulan bahwa meningkatkan keterampilan berbicara dipengaruhi oleh lingkungan sekitar dan motivasi dari guru selain itu kemampuan berbicara dapat dibagi dari beberapa aspek seperti melafalkan bunyi, kosa kata, dan membuat kalimat. Kemampuan berbicara anak mencapai $48,14 \%$ dan terjadi penurunan skor yang didapat mencapai $6,67 \%$.

Saran yang dapat diberikan yaitu meningkatkan keterampilan berbicara dapat dilakukan dengan media $b$ oneka tangan dengan melatih sesuai waktu yang tepat untuk anak agar tidak bosan.

\section{REFERENSI}

Agung, A.A.G. (2010). Bahan Kulyah Statitiska Deskriptif. Singaraja: Fakultas Ilmu Pendidikan Ganesha. Arikunto, S. (2010). Prosedur Penelitian Suatu Pendekatan Praktek. Jakarta: Penerbit Rineka.

Cresweel, J.W. (2015). Penelitian Kualitatif Dan Desain Riset. Pustaka pelajar. Yogyakarta.

Dhieni, N., et.al. (2005). Metode Pengembangan Bahasa. Jakarta: Universitas Terbuka.

Hurlock, E.B. (1999). Psikologi Perkembangan. Cet.5 (Penerj. Istiwidayanti, dkk.). Jakarta: Erlangga.

Sugiyono. (2010). Metode Penelitian Pendidikan Pendekatan Kuantitatif, kualitatif, dan $R \& D$. Bandung: Alfabeta.

Suhartono. (2005). Pengembangan Keterampilan Bicara Anak Usia Dini. Jakarta: Departemen Pendidikan Nasional, Direktorat Jenderal Pendidikan Tinggi, Direktorat Pembinaan Pendidikan Tenaga Kependidikan dan Ketenagaan Perguruan Tinggi. 